\title{
An object-based cost of visual filtering
}

\author{
ZHE CHEN \\ Princeton University, Princeton, New Jersey
}

\begin{abstract}
Although evidence for object-based attention has been reported in a variety of paradigms, few studies have examined directly the relationship between efficiency in the processing of targets and the number of intervening distractors. In five experiments, observers judged whether the vertices of two relevant shapes were of the same height. Experiments 1 and 2 manipulated observers' perceptual set so that identical stimulus displays were perceived as containing either intervening or flanking distractors. The observers were faster when the distractors were flanking rather than intervening between the targets. Experiments 3-5 varied the number of intervening distractors directly. The observers' response latencies correlated positively with the distractor set-size. Because the distractors were highly discriminable from the targets and the spatial separation between the targets and their interactions with the adjacent distractors were held constant, it was unlikely that the differential reaction times across the conditions were caused by lateral inhibition or response competitions from the distractors. The results suggest the existence of an object-based filtering cost. The implications of the present data for attentional selection over noncontiguous regions are also discussed.
\end{abstract}

Much of what we see depends on how we parse and organize a visual scene. Recent vision research has shown that, in order to process visual information effectively, we parse our visual world not only into different spatial regions (Posner, 1980; Posner, Snyder, \& Davidson, 1980), but also into potential objects or perceptual groups (Duncan, 1984; Harms \& Bundesen, 1983; Kahneman \& Henik, 1981; Prinzmetal, 1981; Treisman, Kahneman, \& Burkell, 1983). Furthermore, both location- and objectbased reference frames can be employed to code visual information in the same situation (Chen, 1998; Egly, Driver, \& Rafal, 1994; Kramer \& Jacobson, 1991; Lavie \& Driver, 1996; Moore, Yantis, \& Vaughan, 1998). In other words, attention selects the internal representation of both space and object.

In prior behavioral studies, evidence for an objectbased selection has typically been associated with one of following findings: (1) Responses to target are faster and/or more accurate when they are part of a single object than when they are parts of two objects (Baylis, 1994; Baylis \& Driver, 1993; Behrmann, Zemel, \& Mozer, 1998; Duncan, 1984; Lavie \& Driver, 1996); (2) response latencies are shorter when the switching of attention is within an object rather than between two objects (Chen, 1998; Egly et al., 1994; Moore et al., 1998); (3) response to a target stimulus is delayed when its surrounding distractors are from the same perceptual group, relative to different groups (Baylis \& Driver, 1992; Driver \& Baylis,

I am grateful to Ronald Kinchla and Anne Treisman for their support for the research and their invaluable comments on a previous draft of this manuscript. I also thank Kyle Cave, Arthur Kramer, Steven Yantis, and an anonymous reviewer for their helpful comments. Correspondence concerning this article should be addressed to $Z$. Chen, Department of Psychology, University of Mississippi, University, MS 38677 (e-mail: zhechen@olemiss.edu).
1989; Harms \& Bundesen, 1983; Kramer \& Jacobson, 1991 ), or when its location is the predicted location of a previously checked moving object rather than other locations (Tipper, Driver, \& Weaver, 1991; Tipper, Weaver, Jerreat, \& Burak, 1994); and finally, (4) positive priming, rather than negative priming (Tipper, 1985), is found to accrue to the probe target in a negative-priming paradigm when the prime target and the distractors are perceptually grouped (Fuentes, Humphreys, Agis, Carmona, $\&$ Catena, 1998). Although all of these findings are undoubtedly different aspects of an object effect, the term may entail an additional phenomenon: a positive correlation between observers' response latencies to a target (or targets) and the number of distractors to be filtered out in a nonsearch task. ${ }^{1}$ Borrowing the term filtering cost from Kahneman, Treisman, and Burkell (1983), I will refer to this type of filtering cost as an object-based filtering cost.

Please note that my use of the term object-based filtering cost does not entail that all filtering cost is object based. Just as both space and object can be used as reference frames to code visual information (Chen, 1998; Egly et al., 1994; Kramer \& Jacobson, 1991; Lavie \& Driver, 1996; Moore et al., 1998), filtering costs can be object based and/or location based, depending on the specific task demand. For example, in B. A. Eriksen and C. W. Eriksen's (1974) study, observers responded to a target letter presented either alone or with other flanking letters. The primary manipulations in the study were the separation between the target and the flankers $\left(0.06^{\circ}, 0.5^{\circ}\right.$, or $\left.1^{\circ}\right)$ and the type of flankers used (target and flankers identical, target and flankers different but in the same response category, or target and flankers different and in different response categories). Among other important findings, the results most relevant to the present paper are that there was a decrease in observers' response latencies as sepa- 
One Object

A

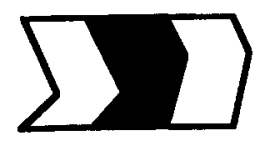

$\mathrm{C}$

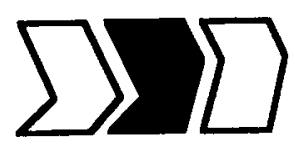

E

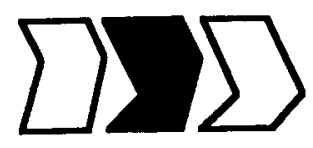

B

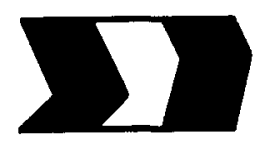

$\mathrm{D}$

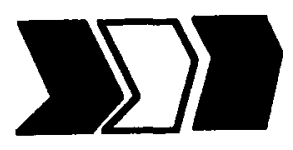

$\mathrm{F}$

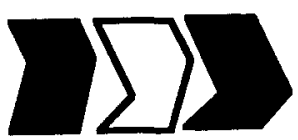

Red

Green

Figure 1. Examples of stimulus displays used in Baylis (1994). The displays are labeled as containing either one or two objects from the perspective of a participant who is instructed to attend only to the red objects. The task was to compare the relative position of the two vertices of the red target object(s) and to indicate which one was lower in position. A: joined one-object condition. B: joined two-object condition. C: separated congruent one-object condition. D: separated congruent two-object condition. E: separated incongruent one-object condition. F: separated incongruent two-object condition. Note. From "Visual Attention and Objects: Two-Object Cost With Equal Convexity," by G. C. Baylis, 1994, Journal of Experimental Psychology: Human Perception \& Performance, 20, p. 209. Copyright 1994 by the American Psychological Association. Adapted with permission.

ration between the target and the flankers increased and that, at $0.06^{\circ}$ target-distractur separation, observers took longer to respond to the target letter when it was flanked by the same letters than when it was presented alone. Whereas the former result suggested the influence of a space-based filtering cost, the nature of the cost in the latter one is uncleai: It could be space based, object based, or both.

Filtering cost has been reported in a number of other studies as well (C. W. Eriksen \& Hoffman, 1972; C. W. Eriksen \& Schultz, 1978; Heinze et al., 1994; Kahneman et al., 1983; Treisman et al., 1983). It has been noted that observers were faster to identify a target letter or to read a word when it was displayed alone, rather than with distractors (C. W. Eriksen \& Hoffman, 1972; Kahneman et al., 1983). This was so even when the distractors were composed of items from a completely different category, such as black disks (C. W. Eriksen \& Hoffman, 1972), colored shapes (C. W. Eriksen \& Schultz, 1978), or a dot patch (Kahneman et al., 1983) Kahnemen et al. further discovered that when the location of a target word was unpredictable, the time it took a participant to read the word increased with the number of irrelevant shapes in the display. The effect was eliminated, however, when the target location was precued. This result suggests that the mechanism mediating the filtering cost may be location based.

Filtering cost may also be implicated in the studies of Baylis and Driver (1993) and Baylis (1994), although the researchers did not interpret their data in that way. In these studies, observers were shown displays consisting of three horizontally aligned red and green shapes (see Figure 1). The task was to compare the two vertices of the target shape(s) and to determine which was lower in position. Through the manipulation of the observers' perceptual set, the relevant target features could be seen as parts of either a single object (when the target was the center shape) or two objects (when the targets were the two outer shapes). The main finding was that observers were faster to perform the task when the target features were parts of a single object than they were when the target features were parts of two objects.

Baylis and Driver (1993; Baylis, 1994) interpreted their data from the perspective of the target features, whether they were on one or two objects. This approach emphasizes the difficulty in attending to two objects simultaneously. An alternative way to account for the data is from the perspective of the distractors, and such an approach stresses the cost of filtering out irrelevant ob- 
jects. If one thinks of nonattended objects as distractors, the two distractors in the one-object condition were always outside the critical vertices to be compared, whereas the one distractor in the two-object condition was always between the two target vertices. Assuming that objects within one's attentional field receive more detailed processing than objects outside the attentional field (C. W. Eriksen \& Hoffman, 1972), the one-object advantage could be due to a difference in distractor position (thus emphasizing a location-based filtering cost) or to a difference in the presence or absence of an intervening distractor between targets (thus emphasizing an objectbased filtering cost).

It is important to point out that, in the studies of Baylis and Driver (1993), and Baylis (1994), the stimuli were intended to be parsed in such a way that the middle region in the two-object condition and the outer regions in the one-object condition should be perceived as ground. If the observers indeed parsed the stimulus displays in that way, the above-mentioned alternative interpretation of the data would be less likely. However, in the experiments that the present series of experiments modeled most closely (i.e., the experiment in Baylis and Experiment 2 in Baylis \& Driver, 1993), such a parsing would have been very difficult, for the following reason. The most likely stimulus displays to yield figure-ground parsing in the Baylis study were those in the joined condition, where all the shapes were connected (see Figures $1 \mathrm{~A}$ and 1B). However, these stimulus displays made up only one fourth of the total trials. Given that the remaining three fourths of the trials consisted of physically separated shapes, with distractor shapes sharing neither the contour nor the color of the target shapes on two thirds of those trials, it would be hard not to perceive the distractor shapes as individual objects.

Treisman, Kahneman, and Burkell (Kahneman et al., 1983; Treisman et al., 1983) were among the first to report the relationship between perceptual objects and the cost of visual filtering. They noted that, when a target word appeared unpredictably on either side of fixation, observers spent less time in reading the word when the word was placed inside an irrelevant shape than when the word and the shape were on the opposite side of fixation (Treisman et al., 1983). Their result suggests that grouping an irrelevant stimulus with a relevant one could reduce the filtering cost associated with the irrelevant stimulus. Recently, Fuentes and his colleagues (Fuentes et al., 1998) reported a similar grouping effect, using a negative-priming paradigm (Tipper, 1985). They showed observers pairs of trials consisting of a target letter with two flanking distractors. The observers' task was to view the prime trial (the $n$ trial) but to respond to the target letter on the probe trial (the $n+1$ trial). When the target and the flankers were separated, the usual negative-priming effect was found: The observers were slower to respond to the probe target when it was the same as the prime distractors than when the two were unrelated. However, when the target and the distractors were grouped by a rectangular outline on the prime trial, the result was reversed: The observers were faster to respond to the probe target when it was the same as the prime distractors than when the two were unrelated. The fact that a grouping effect was found in both studies suggests the existence of an object-based filtering cost.

Using a same-different matching task, the present experiments adopted a novel approach to demonstrate the relationship between visual perception and object-based allocation of attention. They differ from other studies in two important ways. First, whereas the above-mentioned experiments manipulated the grouping strength between the target and the distractors, the experiments reported in this paper varied the number of distractors directly. Second, because the separation between the targets and their adjacent distractors were held constant across conditions, the sensory interactions between the targets and their surrounding distractors were controlled in the present experiments. In Experiments 1 and 2, I sought to establish the existence of the filtering cost, using a paradigm similar to that of Baylis (1994). In Experiments 3-5, I further investigated the possibility that the filtering cost is object based by varying the number of intervening distractors between the targets while keeping constant both the spatial locations of the targets, relative to the distractors, and their interactions.

\section{EXPERIMENT 1}

The paradigm employed in Experiment 1 was modeled after that of Baylis (1994). As in the Baylis study, the observers' perceptual set was manipulated so that the irrelevant objects could be seen as either being between or flanking the target objects. Unlike his study, however, the critical features for comparison were always parts of two objects, and the task was to make same-different judgments regarding the relative height of two target vertices. This particular design was chosen because it allowed the experimenter to examine the cost of visual filtering while keeping constant the sensory aspects of the stimulus array. If the one-object advantage reported by Baylis was caused solely by the differential number of target objects, no difference in reaction time and/or accuracy should be found between the critical experimental conditions in the present experiment, because it employed an equal number of target objects in all conditions. If, however, we still find differential reaction times and/or accuracy, the one-object advantage is at least partly contributed to by a difference in distractor position, a difference in the number of intervening distractors between targets, or both.

\section{Method}

Participants. Sixteen Princeton undergraduates, between 18 and 26 years old, participated in the study to satisfy course requirements of the psychology department. All reported having normal or corrected-to-normal vision. None knew the purpose of the experiment in advance.

Apparatus and Stimuli. A Macintosh IIci computer with a 13in. RGB monitor was used to present stimuli and record responses. 
Target-In

A

Joined

Consistent

B

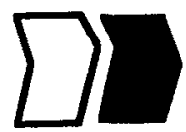

C

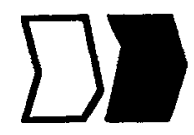

Inconsistent

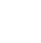

D

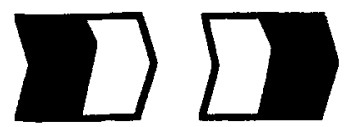

E

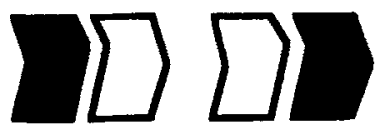

F
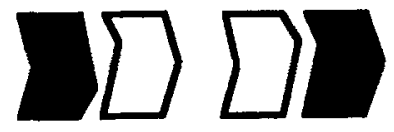

\section{Blue}

\section{Target-Out}
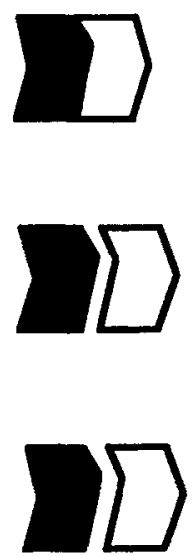

Red

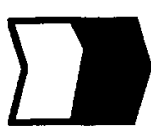

10

\begin{abstract}
Figure 2. Examples of stimulus displays from Experiment 1. The displays are labeled from the perspective of an observer attending only to the red shapes. The observers made same-different judgments regarding the relative height of the two outer vertices of the targets in the target-in conditions. The same-different judgments concerned the relative height of the two inner vertices of the targets in the target-out conditions. Note that the separation between the target vertices was identical in the two joined conditions. The six experimental conditions were in-joined (A), in-consistent (B), in-inconsistent (C), out-joined (D), out-consistent (E), and out-inconsistent (F).
\end{abstract}

The participants viewed the monitor from a distance of approximately $60 \mathrm{~cm}$ in a dimly lit room. Commercially available graphic (Superpaint 3.0) programs and experimental (VScope 1.2) programs were used to generate and display stimuli and to record respuıses.

Four red and blue chevron-like shapes made up the stimulus display, as is shown in Figure 2. Each shape subtended $1.91^{\circ}$ of visual angle in length and $1.14^{\circ}$ in width. The entire display subtended $5.7^{\circ}$ horizontally when the targets were joined with the distractors and $6.4^{\circ}$ when they were separated (the horizontal separation between the shapes was $0.35^{\circ}$ ).

Design and Procedure. The experiment was a mixed design, with target color as the between-subjects variable and the locations of the targets and the target-distractor relationship as the withinsubjects variables. The latter had three levels: joined, when the targets and the distractors were connected; consistent or inconsistent, when the shapes were separated, with congruent or incongruent vertices for the targets and their adjacent distractors. The observers were instructed to attend to either the red or the blue shapes only. They made same-different responses regarding the relative height of the two outer vertices of the target shapes if the latter were the two innermost shapes. If the target shapes were the two outermost shapes of the stimulus pattern, the comparison was between the two inner vertices of these shapes. Please note that the critical edges for comparison were always parts of two different objects and that the spatial separations between the target vertices in the two joined conditions were identical (both were $3.42^{\circ}$ of visual angle horizontally). Consequently, the two joined conditions vere of primary interest here. The other four conditions were included primarily to encourage the participants to follow the instructions for the experiment. If the experiment had contained only the joined conditions, the observers could have performed the task even though they focused attention on the distractors. By making half the trials inconsistent trials, in which the contour of one of the distractors was incongruent with the contour of a target, the observers would be more likely to attend to the target objects. Otherwise, they would get negative feedback on at least half the trials. Altogether, the experiment had six conditions: in-joined (IJ), in-consistent (IC), in-inconsistent (II), out-joined (OJ), out-consistent (OC), and out-inconsistent (OI), where in- and out- refer to the position of the target shapes, relative to the distractors.

Each trial started with an asterisk, serving as a fixation point, in the center of the screen for $500 \mathrm{msec}$. After a blank period of $200 \mathrm{msec}$, the stimulus display was presented at the center of the monitor for $150 \mathrm{msec}$. The participants were to press one key if the two critical vertices were at the same level of height and a different key otherwise (the designated two krys were " $z$ " and "/," and they were counterbalanced across observers). After the observer responded, either a "+" (meaning the response was right) or a "-" (meaning the response was wrong) would appear on the screen. If no response was made within $4 \mathrm{sec}$ after the display onset, a " 0 " would appear. The intertrial interval was $900 \mathrm{msec}$.

Both speed and accuracy were stressed. After 32 practice trials, each observer performed five blocks of 96 test trials, half of them being same trials, and the other half different trials. Twice as many inconsistent trials as either joined or consistent trials were included in each block. The whole experiment took approximately $50 \mathrm{~min}$ to complete.

\section{Results and Discussion}

The reaction time and accuracy data are presented in Table 1 .

A mixed-design analysis of variance (ANOVA) on reaction times ${ }^{2}$ showed faster response times for the target- 
Table 1

Mean Reaction Times (in Milliseconds) and Error Rates (Percent Incorrect), With Standard Deviations, for Experiment 1

\begin{tabular}{|c|c|c|c|c|c|c|c|c|c|c|c|c|}
\hline \multirow[b]{4}{*}{ Position } & \multicolumn{12}{|c|}{ Target-Distractor Relationship } \\
\hline & \multicolumn{4}{|c|}{ Joined } & \multicolumn{4}{|c|}{ Consistent } & \multicolumn{4}{|c|}{ Inconsistent } \\
\hline & \multicolumn{2}{|c|}{ Reaction Time } & \multicolumn{2}{|c|}{ Error Rate } & \multicolumn{2}{|c|}{ Reaction Time } & \multicolumn{2}{|c|}{ Error Rate } & \multicolumn{2}{|c|}{ Reaction Time } & \multicolumn{2}{|c|}{ Error Rate } \\
\hline & $M$ & $S D$ & $M$ & $S D$ & $M$ & $S D$ & $M$ & $S D$ & $M$ & $S D$ & $M$ & $S D$ \\
\hline Target-in & 992 & 305 & 9.7 & 11.2 & 981 & 324 & 8.9 & 11.0 & 1,015 & 296 & 10.1 & 9.9 \\
\hline Target-out & 1,062 & 367 & 18.0 & 17.7 & 1,077 & 350 & 17.2 & 16.1 & 1,112 & 328 & 19.6 & 15.6 \\
\hline
\end{tabular}

Note-The standard deviations shown here represent the between-subjects variability within a condition, not the within-subjects variability across conditions that is of interest in the present paper.

in conditions (996 msec) than for the target-out conditions $[1,084 \mathrm{msec} ; F(1,14)=5.53, p<.04]$. Planned mean comparisons subsequently revealed that the participants were faster in the IJ $(992 \mathrm{msec})$ and II $(1,015 \mathrm{msec})$ conditions than in the OJ $(1,062 \mathrm{msec})$ and OI $(1,112 \mathrm{msec})$ conditions $[t(15)=2.21, p<.05$, and $t(15)=2.69, p<.02$, respectively]. The difference between the IC $(981 \mathrm{msec})$ and the OC $(1,077 \mathrm{msec})$ conditions did not reach significance $[t(15)=1.81, p=.09]$. An ANOVA on accuracy did not show any main effects or interactions at a .05 significance level, even though more errors occurred in the out conditions $(18.3 \%$ error rate) than in the in conditions $[9.6 \%$ error rate; $F(1,14)=4.11$, $p<.07]$. No other statistical analyses were performed.

The most important finding is that the observers were slower to perform the task when the distractors were between rather than flanking the targets. This aspect of the data is, in fact, similar to the findings of Baylis (1994), and Baylis and Driver (1993), whose observers were also slower when the distractors were outside the target than the other way around. Since the number of target objects was not varied in the present experiment and the observers still had differential response times across conditions, these data raise the possibility that a differential degree of filtering cost across experimental conditions could be partially responsible for the object effect reported by Baylis and by Baylis and Driver (1993).

The experiment did not find any consistency effect between the targets and the distractors. In prior research, the consistency effect appeared to vary across studies. On the one hand, Kramer and Jacobson (1991) showed the dependence of the consistency effect on the grouping strength between the targets and the distractors. They found the effect when the target and the distractors were seen as one perceptual group, but did not find it when they were seen as belonging to two perceptual groups. On the other hand, Baylis and Driver (1993) and Baylis (1994) observed the consistency effect repeatedly in their studies, although the target(s) and distractors clearly belonged to two perceptual groups. The lack of a consistency effect in Experiment 1 could be caused either by a lack of statistical power or by methodological differences among the studies. Although Experiment 1 was similar to the Baylis study in design, there were still some po- tentially important differences between the two. Whereas one of the target vertices was not aligned with its adjacent distractor in the present experiment, neither of them was aligned in the studies of Baylis, and of Baylis and Driver (1993). The fact that the latter had more target sides incongruent with the distractor sides than did the former could have led to the observed consistency effect in their studies and the lack of it in Experiment 1.

\section{EXPERIMENT 2}

In Experiment 2, I sought to replicate the results of Experiment 1, using a slightly different design. To make stimulus displays more similar to those of Baylis (1994), a new object was inserted at the center of the stimulus display, as is shown in Figure 3. The inserted object could be seen as belonging with either the target or the distractor. The observers again made same-different comparisons regarding the relative height of the targets, as defined by colors. As before, the target vertices for comparison belonged to two objects. The main question was whether the observers' response latencies would vary as a function of their perceptual set.

\section{Method}

Participants. Fifteen Princeton undergraduates from the same participant pool as before participated in the study to satisfy a course requirement. None had taken part in Experiment 1, and none knew the purpose of the study in advance.

Apparatus and Stimuli. Both the apparatus and the stimuli were the same as those in Experiment 1, except for the insertion of a new shape and, consequently, the horizontal expansion of the stimulus display to $7.1^{\circ}$ in both the consistent and the inconsistent conditions.

Design and Procedure. Except for the following changes, the design and the procedure were otherwise identical to those of Experiment 1 . Owing to the insertion of the new object, the comparison was between the two outer vertices of the target shapes when the stimulus display contained only two target elements. When there were three target elements, the comparison was between the two inner vertices of the two outer target objects. The three target-in conditions (i.e., IJ, IC, and II) contained two target objects, whereas the three target-out conditions (i.e., OJ, OC, and OI), now had three stimuli in the target color, although the observers knew that only the two outer shapes were designated as targets. As in Experiment 1 , the spatial separations between the critical target vertices were identical in the two joined conditions. Again, the participants 
Target-In

A

Joined

Consistent

B

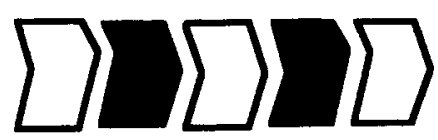

$\mathrm{C}$

Inconsistent

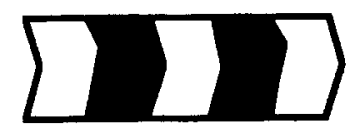

$\mathrm{E}$

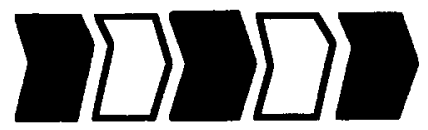

F

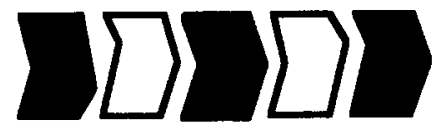

D
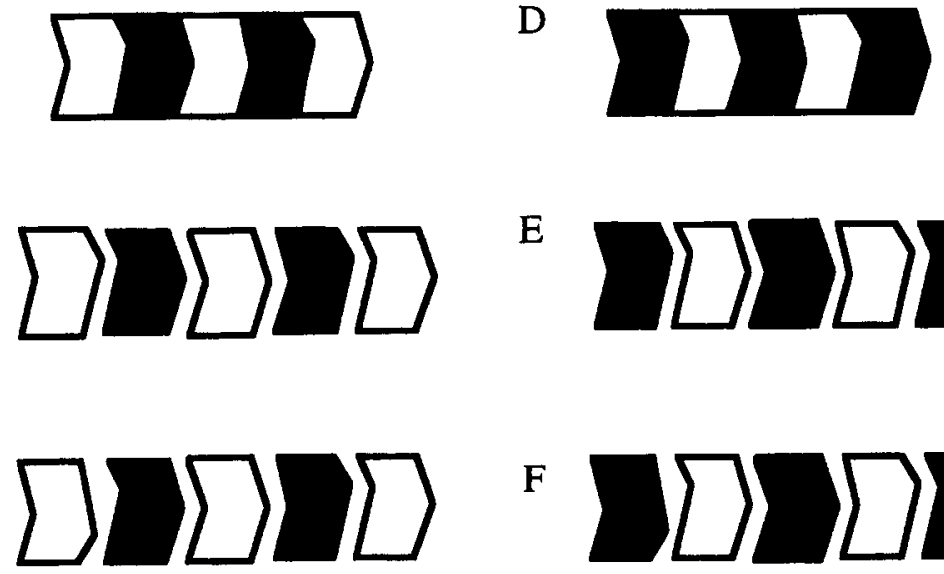

Target-Out

Red

$\square$ Blue

Figure 3. Examples of stimulus displays from Experiment 2. The displays are labeled from the perspective of an observer attending only to the red shapes. The observers made same-different judgments regarding the relative height of the two outer vertices of the targets in the target-in conditions. The samedifferent judgments concerned the relative height of the two inner vertices of the two outer targets in the target-out conditions. The six experimental conditions were in-joined $(A)$, in-consistent $(B)$, in-inconsistent (C), out-joined (D), out-consistent (E), and out-inconsistent (F).

were instructed to attend exclusively to either the red or the blue shapes and to perform the same-different judgment task as quickly and as accurately as possible.

\section{Results and Discussion}

The data are shown in Table 2. Only 12 of the 15 participants' data were included in the analysis. Two participants did not complete the experiment, owing to computer failures, and the third person had an extraordinarily high error rate (45\% errors in Block 1 and $34 \%$ in Block 2 ). An ANOVA found faster reaction time, as well as higher accuracy, in the target-in conditions $(1,036 \mathrm{msec}$, with $10 \%$ errors) than in the target-out ones $[1,122 \mathrm{msec}$, with $19.1 \%$ error; $F(1,10)=6.52, p<.03$, and $F(1,10)=$ $8.68, p<.02$, respectively]. Paired $t$ tests further showed that, for the two critical joined conditions, although the separations between the edges for comparison were exactly the same, the responses were both faster $[1,028 \mathrm{msec}$ in the IJ condition vs. $1,122 \mathrm{msec}$ in the OJ condition; $t(11)=2.94 . p<.02]$ and more accurate $[10.2 \%$ in the IJ condition vs. $18.4 \%$ in the OJ condition; $t(11)=2.27$, $p<.05]$ when the judgments were made with regard to the two outer vertices in the IJ condition, rather than the two inner vertices in the $\mathrm{OJ}$ condition. The observers also made fewer errors in the IC condition than in the OC condition $[6.6 \%$ vs. $18.5 \%$ error rates; $t(11)=4.76, p<$ $.0001]$. Furthermore, the reaction time differences between the two consistent conditions $(1,012 \mathrm{msec}$ in the IC condition vs. $1,101 \mathrm{msec}$ in the OC condition) and their inconsistent counterparts $(1,069 \mathrm{msec}$ in the II condition vs. $1,144 \mathrm{msec}$ in the OI condition) approached significance $[t(11)=2.13, p<.06$, and $t(11)=2.15, p<.06$, respectively]. No significant difference in accuracy was found between the II (13.3\% error) and the OI $(20.4 \%$

Table 2

Mean Reaction Times (in Milliseconds) and Error Rates (Percent Incorrect), With Standard Deviations, for Experiment 2

\begin{tabular}{|c|c|c|c|c|c|c|c|c|c|c|c|c|}
\hline \multirow[b]{4}{*}{ Position } & \multicolumn{12}{|c|}{ Target-Distractor Relationship } \\
\hline & \multicolumn{4}{|c|}{ Joined } & \multicolumn{4}{|c|}{ Consistent } & \multicolumn{4}{|c|}{ Inconsistent } \\
\hline & \multicolumn{2}{|c|}{ Reaction Time } & \multicolumn{2}{|c|}{ Error Rate } & \multicolumn{2}{|c|}{ Reaction Time } & \multicolumn{2}{|c|}{ Error Rate } & \multicolumn{2}{|c|}{ Reaction Time } & \multicolumn{2}{|c|}{ Error Rate } \\
\hline & $M$ & $S D$ & $M$ & $S D$ & $M$ & $S D$ & $M$ & $S D$ & $M$ & $S D$ & $M$ & $S D$ \\
\hline Target-in & 1,028 & 295 & 10.2 & 6.7 & 1,012 & 252 & 6.6 & 4.7 & 1,069 & 301 & 13.3 & 10.1 \\
\hline Target-out & 1,122 & 318 & 18.4 & 15.1 & 1,101 & 296 & 18.5 & 11.9 & 1,144 & 285 & 20.4 & 12.5 \\
\hline
\end{tabular}


error) conditions. No other statistical analyses were performed on the data.

The results of Experiment 2 were very similar to those of Experiment 1. In both experiments, regardless of whether there was an object in the center of the stimulus pattern, the observers were more efficient in comparing the relative height between the two edges when the target vertices contained fewer, rather than more, irrelevant items. It is important to point out that, in Experiment 2, the observers had been forewarned that, although the central shape sometimes had the same color as the target objects, it would never be designated as a target. Together with the findings of Experiment 1, these results support the notion that the efficiency of processing of the target(s) varies as a function of the filtering cost of the distractors.

Compared with Experiment 1, Experiment 2 contained an extra object at the center of the display. One would expect that the added item would increase the observers' overall response latencies. Although the observers appeared to take longer to respond in Experiment 2 than in Experiment 1 (with average reaction times of 1,079 and $1,040 \mathrm{msec}$ for Experiments 2 and 1, respectively), a combined analysis across the experiments showed no significant effect of experiment $(F<1)$. Rather, there was a highly significant distractor position effect $[F(1,26)=$ $11.53, p<.001]$, as well as a distractor consistency effect $[F(2,52)=3.98, p<.03]$. The last effect implies that the lack of a consistency effect in the two experiments when they were analyzed individually could be due to a lack of statistical power.

Admittedly, neither Experiment 1 nor Experiment 2 distinguished an object-based selection mechanism from a location-based one. To explain the data within the framework of an object-based model, one could argue that the differential response times across the conditions were caused by the different number of intervening distractors between the target-in and the target-out conditions. Because these distractors were potential sources of interference and were presented as sudden onsets (Kramer \& Hahn, 1995), they competed for attentional resources. Thus, the more distractors needed to be filtered out, the less efficient the target processing would be. To explain the data from the perspective of a location-based model, one could emphasize the difference in distractor positions between the target-in and the target-out conditions. Since distractors within one's spotlight cause more interference to the processing of the targets than do distractors at other locations, longer reaction times from the targetout condition would be expected.

Although it is difficult to distinguish an object-based account from a location-based one in the previous two experiments, given that an object-based filtering cost stresses the importance of the number of distractors to be filtered out and a location-based filtering cost emphasizes the importance of the spatial separation between targets and distractors, the two accounts can lead to very dif- ferent predictions in the right paradigm. Imagine that observers perform a type of same-different matching task involving two relevant objects that is similar to that in the previous experiments and that the principle manipulation in the experiment is the number of intervening distractors between the targets. Whereas an object-based account would predict a positive correlation between the observers' response latencies and/or accuracy and the number of distractors, a location-based account would predict no such correlation. Experiment 3 was conducted in order to differentiate between the two accounts.

\section{EXPERIMENT 3}

If filtering cost is object based, so long as irrelevant objects interfere with the processing of the targets, their exclusion should consume resources, and there should be a positive correlation between observers' reaction times to the targets and the number of irrelevant objects to be filtered out. Location information about the targets should not be a deciding factor in the demonstration of an object-based filtering cost. Experiment 3 tested this hypothesis by varying the number of intervening distractors between the targets, while keeping constant both the separation of the targets and their lateral interaction with the distractors. The task was to compare the relative height of the two inner vertices of the target objects and to make a speeded same-different response on each trial.

\section{Method}

Participants. Twelve naive Princeton undergraduates, between the ages of 18 and 26, participated in the study. They all reported having normal or corrected-to-normal vision. Each was paid \$4. As before, none had taken part in the previous experiments, and none knew the purpose of the experiment beforehand.

Apparatus and Stimuli. The apparatus and stimuli were the same as those in Experiment 1, except for the following three changes. First, the target objects were at the two far ends of the display, and the comparison was between the two inner vertices of the target shapes (see Figure 4). The horizontal separation between the targets was $3.42^{\circ}$, and the entire display subtended $5.7^{\circ}$. Whereas the width of the distractor(s) was $2.72^{\circ}$ and $1.19^{\circ}$ in the one- and two-distractor conditions, respectively, the horizontal separation between the target vertices and their immediately adjacent distractors was $0.35^{\circ}$ in both cases. Second, the relationship between the vertices of the distractor(s) and the vertex of their adjacent target was that of being orthogonal to each other, and the targets and the distractors were always separated. Third, to discourage the observers from adopting external reference frames when performing the task, the stimulus array was presented at locations randomly selected within the boundary of an invisible $8.69^{\circ} \times 4.59^{\circ}$ rectangle. Please note that, although the absolute location of the stimulus array varied from trial to trial, the positions of the targets, relative to the distractors, remained the same throughout the experiment.

Design and Procedure. The design and procedure were again similar to those of Experiment 1. As in the previous experiments, half the participants were instructed to attend to the red shapes, and the other half to the blue shapes. The within-subjects variable was the number of distractors between the targets. Its three levels corresponded to the three experimental conditions: no distractor (0D), one distractor (1D), and two distractors (2D). 


\begin{abstract}
A
No-distractor

$\square$

D

B

One-distractor

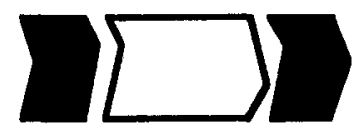

C

Two-distractor

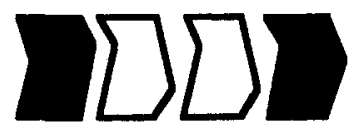

Red

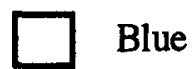

Figure 4. Examples of stimulus displays from Experiment 3. The displays are labeled from the perspective of an observer attending only to the red shapes. The observers made same-different judgments regarding the relative height of the two inner vertices of the target shapes. The three experimental conditions were no distractor (A), one distractor (B), and two distractors (C).
\end{abstract}

Each observer performed two blocks of 192 trials, yielding 128 trials per condition. The total experiment took approximately half an hour to complete.

\section{Results and Discussion}

The reaction time and accuracy data are given in Table 3. An ANOVA on reaction times showed a significant effect for condition $[F(2,20)=23.98, p<.001]$. Paired $t$ tests found faster reaction times in the $0 \mathrm{D}$ condition $(872 \mathrm{msec})$ than in the $1 \mathrm{D}$ condition $[926 \mathrm{msec}$; $t(11)=3.66, p<.001]$, as well as faster reaction times in the $1 \mathrm{D}$ condition than in the $2 \mathrm{D}$ condition [926 vs. $957 \mathrm{msec} ; t(11)=2.75, p<.02$.

The same analyses were performed on the accuracy data. There was a significant effect for condition $[F(2,20)=17.98, p<.001]$. Paired $t$ tests indicated that the observers were more accurate in the $0 \mathrm{D}$ condition $(10.7 \%$ error) than in the $1 \mathrm{D}$ condition $[13.8 \%$ error; $t(11)=4.53, p<.001]$. They also made fewer errors in the $1 \mathrm{D}$ condition than in the $2 \mathrm{D}$ condition $[13.8 \%$ error vs. $17 \%$ error; $t(11)=2.9, p<.02]$.

Our data suggest that the observers' performance was influenced by the number of intervening distractors, despite the fact that the distractors were highly discriminable from the targets and that both the locations of the targets relative to the distractors and the interaction between the targets and their immediately adjacent distractors were held constant across the experimental conditions. The data support the notion of an object-based filtering cost.

However, Experiment 3 contained a potential confound: The stimulus display in the $2 \mathrm{D}$ condition was more complex than the stimulus display in either the $0 \mathrm{D}$ condition or the $1 \mathrm{D}$ condition. The observers' response latencies could be impaired, not by the number of distractors per se, but by the extra number of distracting lines and angles associated with the stimulus displays in the $2 \mathrm{D}$ condition. To rule out a confusability account as a possible interpretation of the data, the next two experiments were conducted.

\section{EXPERIMENT 4A}

Experiment $4 \mathrm{~A}$ was essentially the same as Experiment 3 , with two major differences. First, instead of using single colored shapes, as in the previous experiments, the shapes in this study contained a black outline. Second, rather than having three conditions that contained zero, one, or two distractors, the three conditions in the new experiment contained no distractor, a simple distractor (SD), and a complex distractor (CD). Whereas the SD was made up of a colored shape with a black outline, the $C D$ was made up of the same shape plus some extra black lines (see Figure 5). If the differential response latencies between the $1 \mathrm{D}$ and the $2 \mathrm{D}$ conditions in Experiment 3 was caused by the differential number of distractors between

Table 3

Mean Reaction Times (in Milliseconds) and Error Rates (Percent Incorrect),

With Standard Deviations, for Experiment 3

\begin{tabular}{lccccc}
\hline & \multicolumn{2}{c}{ Reaction Time } & & \multicolumn{2}{c}{ Error Rate } \\
\cline { 2 - 3 } \cline { 5 - 6 } Condition & $M$ & $S D$ & & $M$ & $S D$ \\
\hline No distractor & 872 & 220 & 10.7 & 5.7 \\
One distractor & 926 & 233 & 13.8 & 6.6 \\
Two distractors & 957 & 244 & & 17.0 & 6.4 \\
\hline
\end{tabular}



Red with black outline

$\square$ Blue with black outline

\begin{abstract}
Figure 5. Examples of stimulus displays from Experiment 4A. The displays are labeled from the perspective of an observer attending only to the red shapes. The observers made same-different judgments regarding the relative height of the two inner vertices of the target shapes. The three experimental conditions were no distractor (A), simple distractor (B), and complex distractor (C).
\end{abstract}

targets, no difference in reaction times should be found between the $\mathrm{SD}$ and the $\mathrm{CD}$ conditions in the present experiment, because the number of distractors was held constant. If, however, the previously found filtering cost was, in fact, due to a differential degree of confusability between the two conditions, we should expect to find longer reaction time in the $\mathrm{CD}$ condition than in the SD condition.

\section{METHOD}

Participants. Twelve naive undergraduates, between the ages of 18 and 26, from the University of Mississippi participated in the study in exchange for psychology course credit. All had normal or corrected-to-normal vision by self-report. Again, none knew the purpose of the study beforehand.

Apparatus and Stimuli. The apparatus remained the same as before, except that a Power Macintosh 6100/66 was used to run the study. Except for the following changes, the stimuli were the same as those in Experiment 3. First, each shape contained a black outline, which was $0.04^{\circ}$ in width. This, however, did not change the size of the individual shape or the overall size of the entire display. Second, there was only one distractor in both the SD and the CD conditions, with the distractor in the latter condition containing two more black lines; each was $0.04^{\circ}$ in width, and they had exactly the same contours as the distractor shapes in the 2D condition of Experiment 3 (see Figure 4).

Design and Procedure. The design and procedure were similar to those of Experiment 3. The within-subjects variable was the type of distractors between the targets. The three conditions were $0 \mathrm{D}$, $\mathrm{SD}$, and $\mathrm{CD}$.

\section{Results and Discussion}

Table 4 contains the reaction time and accuracy data. An ANOVA revealed a significant effect for condition $[F(2,20)=5.21, p<.02]$. The observers were faster in the
$0 \mathrm{D}$ condition $(792 \mathrm{msec})$ than in either the SD $(832 \mathrm{msec})$ or the CD condition $[833 \mathrm{msec} ; t(11)=2.53, p<.03$, and $t(11)=2.38, p<.04$, respectively]. No difference was found between the SD and the CD conditions [832 vs. $833 \mathrm{msec} ; t(11)<1$, n.s.].

Accuracy data showed a similar pattern. There was a significant difference for condition $[F(2,20)=6.47, p<$ $.001]$. The observers were more accurate in the $0 \mathrm{D}$ condition (19.3\% error rate) than in the SD condition [ $24.3 \%$ error rate; $t(11)=3.33, p<.001]$. Again, there was no significant difference between the $\mathrm{SD}$ and the $\mathrm{CD}$ conditions $[24.3 \%$ error rate vs. $20.7 \%$ error rate; $t(11)=2.0$, $p>.05]$.

The most important finding of this experiment is that, although the observers' performances were influenced by the presence or absence of a distractor, they were not affected by the degree of confusability associated with the

Table 4

Mean Reaction Times (in Milliseconds) and Error Rates (Percent Incorrect), With Standard Deviations, for Experiments $4 A$ and 4B

\begin{tabular}{|c|c|c|c|c|}
\hline \multirow[b]{2}{*}{ Condition } & \multicolumn{2}{|c|}{ Reaction Time } & \multicolumn{2}{|c|}{ Error Rate } \\
\hline & $M$ & $S D$ & $M$ & $S D$ \\
\hline \multicolumn{5}{|c|}{ Experiment $4 \mathrm{~A}$} \\
\hline No distractor & 792 & 162 & 19.3 & 7.4 \\
\hline Simple distractor & 832 & 195 & 24.3 & 9.0 \\
\hline Complex distractor & 833 & 192 & 20.7 & 7.1 \\
\hline \multicolumn{5}{|c|}{ Experiment 4B } \\
\hline No distractor & 816 & 152 & 17.7 & 7.1 \\
\hline One distractor & 849 & 161 & 21.9 & 8.6 \\
\hline Two distractors & 875 & 172 & 22.6 & 8.6 \\
\hline
\end{tabular}


distractor. This suggests that it is unlikely that the longer reaction times observed in the $2 \mathrm{D}$ condition, relative to the $1 \mathrm{D}$ condition, in Experiment 3 were caused by the greater degree of complexity of the stimulus displays associated with the former condition, at least in the present paradigm. Rather, the efficiency of target selection appears to relate directly to the number of intervening distractors.

It is true that Experiment $4 \mathrm{~A}$ ruled out confusability as the primary cause of the filtering cost in Experiment 3 . Nevertheless, it was still desirable to conduct a further experiment that would involve the manipulation of the distractor set-size while using colored shapes with black outlines.

\section{EXPERIMENT 4B}

Experiment 4B was basically the same as Experiment 3 , except for the change in stimulus displays from solid colored shapes to colored shapes with black outlines. As in Experiment 3, the participants performed a speeded same-different judgment task with regard to the height of the inner vertices of the target shapes, and the primary manipulation of the experiment was the number of distractors between the targets. It was expected that the participants' response latencies would correlate positively with the number of intervening distractors.

\section{Method}

Participants. Sixteen naive undergraduates from the same subject pool as that in Experiment 4A participated in the study. None had taken part in the earlier experiments. None knew the purpose of the experiment beforehand.

Apparatus and Stimuli. The apparatus was the same as that in Experiment 4A. Except for the change from solid colored shapes to colored shapes with black outlines $\left(0.04^{\circ}\right.$ in width $)$, the stimuli were identical to those in Experiment 3.

Design and Procedure. Both the design and the procedure were the same as those in Experiment 3.

\section{Results and Discussion}

Table 4 contains the reaction time and accuracy data. An ANOVA on both reaction times and accuracy showed a significant effect for condition $[F(2,28)=17.33, p<$ .001 , for reaction time, and $F(2,28)=8.78, p<.001$, for accuracy]. The participants were both faster and more accurate in the $0 \mathrm{D}$ condition ( $816 \mathrm{msec}$, with $17.7 \%$ error) than in the $1 \mathrm{D}$ condition [ $849 \mathrm{msec}$, with $21.9 \%$ error; $t(15)=3.75, p<.001$, for reaction time, and $t(15)=3.33$, $p<.001$, for accuracy, respectively]. They were also faster in the $1 \mathrm{D}$ condition than in the $2 \mathrm{D}$ condition $[849 \mathrm{msec} v \mathrm{vs}$. $875 \mathrm{msec} ; t(15)=3.00, p<.001]$. No difference in accuracy was found between the last two conditions $[t(15)<$ 1, n.s.].

Consistent with the results of Experiment 3, the participants in this experiment responded fastest when the targets contained no intervening distractors, next fastest when there was one intervening distractor, and slowest when there were two intervening distractors. Given the re- sults of the last three experiments, it appears that the filtering cost in the present series of experiments is object based.

As was described in the introduction, Kahneman et al. (1983) reported a strong distractor set-size effect when the location of the target was unpredictable. The effect disappeared, however, when the target location was precued. In Experiments 3 and 4B, distractor set-size effects were found despite the fact that the position of the targets relative to the distractors was the same. How can we reconcile these seemingly inconsistent results? One important difference between Kahneman et al.'s study and the present experiments was the number of target objects in the design. Whereas there was only a single target in the study of Kahneman et al., there were two targets here. With only a single target, a precue could presumably guide attention to the target effectively. Once attention arrived at the target, it could zoom in (C. W. Eriksen \& St. James, 1986) and focus directly on the target, leaving all irrelevant objects outside the focus of the attention field. In such a paradigm, the number of irrelevant objects in other parts of the visual field might not matter very much, especially when the distractors were separated from the target by more than $1^{\circ}$ (B. A. Eriksen \& C. W. Eriksen, 1974), as was the case in Kahneman et al.'s study. In contrast, when the display contained two targets with intervening distractors, knowing the location of the targets did not solve all the problems, if attention could not select noncontiguous regions (a more detailed discussion on this issue is presented in the General Discussion section). Since objects compete for attention, the more distractors between the targets, the longer it takes to process the targets-hence, the distractor set-size effects in Experiments 3 and $4 \mathrm{~B}$. This is not to say, of course, that the object-based filtering cost cannot reach an asymptote. Factors such as the attentional load of the task (Lavie \& Cox, 1997) and/or the spatial separation among individual distractors may all affect the extent of the filtering cost. Further research is needed to determine how these factors are related to the object-based filtering cost.

\section{EXPERIMENT 5}

Although the relative location of the targets within a stimulus array did not change over trials in the previous experiments, its absolute location was still unpredictable. Thus, it was possible that the object effects observed in Experiments 3 and 4B were associated with the spatial uncertainty of the stimulus display. To test this, a new experiment was designed, in which the stimulus arrays were presented at exactly the same location throughout the experiment. The distractors were also changed from chevronlike shapes into rectangles, so that the target and the distractors differed not only in color and location, but also in shape. If the observers' response latencies still correlated positively with an increase in the number of distractors between the targets, the notion of an objectbased filtering cost would be strengthened. 


\begin{abstract}
A One-distractor

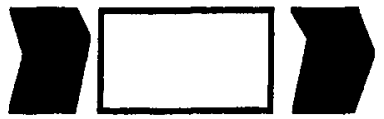

B Two-distractor

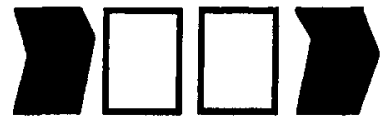

C Three-distractor

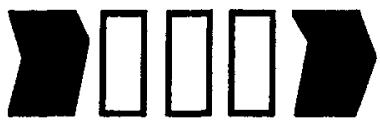

$\square$ Red $\square$ Blue

Figure 6. Examples of stimulus displays from Experiment 5. The displays are labeled from the perspective of an observer attending only to the red shapes. The observers made same-different judgments regarding the relative height of the two inner vertices of the target shapes. The three experimental conditions were one distractor (A), two distractors (B), and three distractors (C).
\end{abstract}

\section{Method}

Participants. Twenty Princeton undergraduates from the same participant pool as that in Experiment 3 took part in the experiment. Each was paid $\$ 3$ for his or her participation. None had taken part in the earlier studies, and none knew the purpose of the experiment beforehand.

Apparatus and Stimuli. The apparatus used in the experiment was the same as that in Experiment 3. Several changes to the stimuli were made. First, the distractors were changed from chevronlike shapes to rectangles. The entire stimulus display now subtended $6.3^{\circ}$, with $4.02^{\circ}$ between the targets. The width of the distractor(s) was $3.32^{\circ}, 1.5^{\circ}$, and $.88^{\circ}$ of visual angle in the $1 \mathrm{D}, 2 \mathrm{D}$, and $3 \mathrm{D}$ conditions, respectively (see Figure 6). Second, the spatial uncertainty regarding the stimulus arrays was removed. All the trials were presented at the center of the screen during the entire experiment.

Design and Procedure. The design and procedure were the same as those in Experiment 3, except that the three conditions now contained one distractor (1D), two distractors (2D), and three distractors (3D). The total experiment took approximately $30 \mathrm{~min}$ to complete.

\section{Results and Discussion}

The reaction time and accuracy data are shown in Table 5. Although an ANOVA on reaction times found a

Table 5

Mean Reaction Times (in Milliseconds) and Error Rates (Percent Incorrect), With Standard Deviations, for Experiment 5

\begin{tabular}{lccccc}
\hline & \multicolumn{2}{c}{ Reaction Time } & & \multicolumn{2}{c}{ Error } \\
\cline { 2 - 3 } \cline { 5 - 6 } Condition & $M$ & $S D$ & & $M$ & $S D$ \\
\hline One distractor & 654 & 111 & & 7.8 & 6.2 \\
Two distractors & 661 & 112 & & 6.7 & 4.6 \\
Three distractors & 666 & 111 & & 7.8 & 5.9 \\
\hline
\end{tabular}

nonsignificant result at $\alpha=.05$ level $[F(2,36)=3.04, p=$ $.06]$, contrast analyses did show a significant linear trend for conditions $[F(1,18)=6.44, p<.03]$. The observers were slowest when there were three intervening distractors $(666 \mathrm{msec})$, next slowest when there were two intervening distractors $(661 \mathrm{msec})$, and fastest when there was only one intervening distractor $(654 \mathrm{msec})$. No other effects were found.

It is true that the object-based filtering cost is not as substantial as that found in the previous experiments. This could be due to the invariant display location of the stimulus array and the distractor shape change in Experiment 5 . These changes also brought a steep decrease in observers' average reaction time and error rate, a drop of $259 \mathrm{msec}$ in reaction time and $7 \%$ in error rate from Experiment 3 to Experiment 5 . What is important, however, is the fact that the observers' performances were still affected by the number of intervening distractors, even though these distractors were very different from the targets. Because the targets (and the distractors, too) were displayed at exactly the same locations throughout the experiment, one would think that an object-based filtering cost should be hard to demonstrate, since the experimental design encouraged the observers to selectively attend to the targets while inhibiting the entire region between the targets. The finding of the differential response latencies across conditions gave strong support to the notion of an object-based filtering cost.

\section{GENERAL DISCUSSION}

Previous work established that grouping distractors with a target could attenuate (Treisman et al., 1983) or 
even reverse the distractor interference effect (Fuentes et al., 1998). Our experiments provide new evidence of the existence of an object-based filtering cost by demonstrating a positive correlation between observers' response time to the targets and the number of distractors. Experiments 1 and 2 showed that observers were faster to compare the height of two target vertices when the distractors were flanking, rather than intervening between, the targets. Besides demonstrating the filtering cost in a perceptual comparison task, these results also pointed out a potentially important confound in the studies of Baylis (1994) and Baylis and Driver (1993), suggesting that the observed one-object advantage reported by these researchers could, in part, be attributed to a differential degree of filtering cost across the experimental conditions. Experiments 3 to 5 tested the notion of an objectbased filtering cost directly by varying the number of intervening distractors between the targets. Despite the difference in shape, color, and location between the targets and the distractors, the observers' response times to the targets increased positively with the increase in the number of intervening distractors. Because both the spatial separation between the targets and their interactions with the adjacent distractors were held constant, it is unlikely that the differential reaction times across the conditions were caused by lateral inhibition or response competitions from the distractors. Neither is it likely that the effects were due to a differential degree of confusability of the stimulus displays across the critical conditions, as was evidenced by the results of Experiment 4A. Rather, the data suggest the existence of an object-based filtering cost.

Please note that I am not arguing for an object-based filtering cost that is spatially invariant, in the sense that spatial location plays no role in the attentional selection process because objects are selected from an internal representation where they are encoded in a spatially invariant way (cf. Vecera \& Farah, 1994; but see Kramer, Weber, \& Watson, 1997). Indeed, I am doubtful that the observers' performance would be more impaired if they had to filter out two superimposed intervening distractors rather than one distractor. However, the fact that the observers' reaction times correlated positively with the number of intervening distractors suggests the existence of a type of filtering cost that is mediated by objects. The data are also consistent with a modified spotlight model that takes into account the number of objects within the spotlight. As Yantis has suggested (Yantis, personal communication, 1998), we can assume that the spotlight must traverse the space between the two target objects, and it may do so more slowly when there are multiple objects in the path, because it lingers at each object. Such a spotlight model would predict a distractor set-size effect observed in the present experiments.

It is unclear whether the filtering cost observed in our experiments was inhibitory in nature. The observers could be delayed because the intervening distractors were within the attentional field and, therefore, received sensory processing automatically, with more distractors taking up more resources. Alternatively, they could be delayed because the application of inhibition took up resources and the amount of resources consumed correlated positively with the amount of inhibition, which, in turn, was influenced by the number of distractors. Although research from both behavioral and neurophysiological studies have cumulated considerable evidence that target facilitation and distractor inhibition are two important components of selective attention (Cepeda, Cave, Bichot, \& Kim, 1998; Chelazzi, Miller, Duncan, \& Desimone, 1993; Keele \& Neill, 1978; Moran \& Desimone, 1985; Neill, 1977; Tipper, 1985; Valdes-Sosa, Bobes, Rodriguez, \& Pinilla, 1998), most of the studies employed only a single target with distractors at other locations. A recent electrophysiological study (Heinze et al., 1994), in which observers' event-related brain potentials (ERPs) were measured, seems to suggest that no suppression was applied to the intervening locations occupied by the distractors. The observers in the Heinze et al. study were shown a horizontal array of four symbols, with two of these locations designated as the relevant locations for a particular block. The task was to press a button when matching symbols were found at the relevant locations. Occasionally, instead of the task-relevant symbols, a task-irrelevant probe would appear at one of the four locations, and the observers were told to ignore these probes. ERPs recorded to the task-irrelevant probes revealed that, when a block required observers to attend to two adjacent locations, the probes that were presented at task-irrelevant locations elicited smaller sensoryevoked electrophysiological responses than did those that were presented at task-relevant locations. In contrast, when a block required observers to attend to two separate locations, no difference in ERPs was found between the probes at the intervening locations and those at the target locations. In light of the above data, it is possible that the filtering cost observed in our experiments was not associated with an inhibitory mechanism working to suppress the intervening distractors.

Our results are related to the issue of visual selection over noncontiguous regions. Evidence regarding whether attention can select noncontiguous regions in the visual field is rather mixed (see Cave \& Bichot, 1999, for a recent review). Results from Posner and his colleagues (Posner et al., 1980) supported a nonsplit beam of attention. Using a dual-cue paradigm, they showed that the detection of a target was enhanced when its location was indicated by a primary cue. However, when its location was indicated by a secondary cue, performance was facilitated only when it was near the location of the primary cue. Similar conclusions were also reached by other researchers, using either cuing paradigms (C. W. Eriksen \& St. James, 1986; C. W. Eriksen \& Yeh, 1985) or other paradigms involving intervening distractors (Heinze et al., 1994; Pan \& Eriksen, 1993). However, opposite findings have been reported by some other researchers (Bichot, Cave, \& Pashler, 1999; Castiello \& Umiltà, 1992; Kramer 
\& Hahn, 1995). Bichot et al. compared observers' performances in a digit identification task when pairs of digits were displayed either simultaneously or successively. They found no difference in accuracy. Kramer and Hahn further discovered that the distribution of attention may depend on the type of stimulus onset employed in an experiment. They noted that, when targets and distractors were presented as sudden onsets, observers were unable to ignore the distractors. In contrast, when the stimuli were presented as nononsets by removing segments of premasks, no interference effect of the distractors was found.

In the present set of experiments, the observers' response time was influenced not only by the presence of the intervening distractors, but also by their set-size. Consistent with the findings of Heinze et al. (1994) and Pan and Eriksen (1993), observers in our experiments found it impossible to ignore the intervening distractors, suggesting their inability to allocate attention to noncontiguous regions of space, at least in the present paradigm with sudden stimulus onsets. The author agrees with the proposal of Kramer and Hahn (1995) that the distribution of attention is a flexible process. Whether attention can be allocated to noncontiguous space may depend, in part, on the presentation method of the stimuli. It is likely that, when stimulus displays involve no sudden onsets, locationbased inhibition can be applied relatively easily over a homogenous region occupied by distractors, resulting in little distractor interference. This may be especially true when the target locations were stationary or precued, as was the case in Kramer and Hahn's study. In contrast, when targets and distractors are presented as sudden onsets, since abrupt visual onsets attract attention automatically (Theeuwes, 1991; Yantis \& Jonides, 1984), observers may find it hard to ignore the distractors, leading to the observed distractor interference effect. Because objects compete for attention (Treisman et al., 1983), the greater number of distractors to be excluded from processing, the longer it would take for the visual system to process the targets - hence, the object-based filtering cost.

If objects compete for attention and sudden onsets attract attention, why did Bichot, Cave, and Pashler (1999, Experiment 6) not find an object-based filtering cost, even though their stimuli were also presented as sudden onsets? In the study of Bichot et al., observers were shown a circular array of eight shapes, followed by a brief display of letters, one in each shape. Two tasks were required on each trial: to determine whether the target shapes (defined by color) were the same or different, and to report as many letters as possible. Accuracy was used as the dependent measure. The main finding of interest is that accuracy was impaired by the presence of distractors between the targets but that there was no distractor set-size effect.

How can we reconcile this difference in data between Bichot et al.'s (1999) study and Experiments 3 and 4B? It is possible that the difference in data was partly due to the way the observers' performance was measured. Whereas response latencies were the primary dependent measure in our experiments, accuracy was used in their study. Because the object-based filtering cost is a rather subtle effect, especially when the distractors are highly distinct from the targets, it is possible that, whereas the effect could be reflected in the observers' reaction times, it could hardly be demonstrated in accuracy (Chen, 1998; Egly et al., 1994). This difference in measurement might have also contributed to the finding of Vecera and Farah (1994, Experiment 2), who observed no difference in the distractor interference effect when the distractors were between a pair of targets and when they were flanking the targets displayed in an overlapping manner. It is worth noting, however, that in both Experiments 3 and 4B of the present paper, the reaction time increase was larger from the $0 \mathrm{D}$ condition to the $1 \mathrm{D}$ condition (an increase of $54 \mathrm{msec}$ in Experiment 3 and $33 \mathrm{msec}$ in Experiment $4 \mathrm{~B}$ ) than from the $1 \mathrm{D}$ condition to the $2 \mathrm{D}$ condition (an increase of $31 \mathrm{msec}$ in Experiment 3 and $26 \mathrm{msec}$ in Experiment 4B). Combining the results from the present experiments and those of Bichot et al., it appears that the first intervening distractor adds a large cost, whereas additional ones add less.

Another of Bichot et al.'s (1999) findings that is of relevance to the present series of experiments was the observation that, although observers reported more letters at the target locations than at the distractor locations, no difference was evident between the intervening distractor locations and other locations. This implies that even though the intervening distractors interfered with target processing, they do not appear to have received more spatial attention than did distractors at other locations, as assessed by the probe technique. Because the probe technique was developed to measure spatial attention (Kim \& Cave, 1995), if the interference effect observed by Bichot et al. in Experiment 6 was mediated by objects rather than by location, such a result would not be unexpected. Taken together, the existing data suggest the existence of an attentional process with multiple reference frames. The demonstration of an object-based filtering cost may depend on the nature of the task, as well as on the measurement employed in the studies.

\section{REFERENCES}

BAYLIS, G. C. (1994). Visual attention and objects: Two-object cost with equal convexity. Journal of Experimental Psychology: Human Perception \& Performance, 20, 208-212.

BAYLIS, G. C., \& DRIVER, J. (1992). Visual parsing and response competition: The effect of grouping factors. Perception \& Psychophysics, 51, 145-162.

BAYLIS, G. C., \& Driver, J. (1993). Visual attention and objects: Evidence for hierarchical coding of location. Journal of Experimental Psychology: Human Perception \& Performance, 19, 451-470.

Behrmann, M., Zemel, R., \& Mozer, M. C. (1998). Object-based attention and occlusion: Evidence from normal participants and a computational model. Journal of Experimental Psychology: Human Perception \& Performance, 24, 1011-1036.

Bichot, N. P., CAVE, K. R., \& PASHLER, H. (1999). Visual selection mediated by location: Feature-based selection of noncontiguous locations. Perception \& Psychophysics, 61, 403-423.

CAstiello, U., \& Umiltà, C. (1992). Splitting focal attention. Journal of Experimental Psychology: Human Perception \& Performance, 18, 837-848.

CAVE, K. R., \& Bichot, N. P. (1999). Visuospatial attention: Beyond a spotlight model. Psychonomic Bulletin \& Review, 6, 204-223. 
Cepeda, N. J., Cave, K. R., Bichot, N. P., \& Kim, M.-S. (1998). Spatial selection via feature-driven inhibition of distractor locations. Perception \& Psychophysics, 60, 727-746.

Chelazzi, L., Miller, E. K., Duncan, J., \& Desimone, R. (1993). A neural basis for visual search in inferior temporal cortex. Nature, 363 , 345-347.

CHEN, Z. (1998). Switching attention within and between objects: The role of subjective organization. Canadian Journal of Experimental Psychology, 52, 7-16.

DRIVER, J., \& BAYLIS, G. C. (1989). Movement and visual attention: The spotlight metaphor breaks down. Journal of Experimental Psychology: Human Perception \& Performance, 15, 448-456.

DUNCAN, J. (1984). Selective attention and the organization of visual information. Journal of Experimental Psychology: General, 113, 501 517.

Egly, R., Driver, J., \& Rafal, R. D. (1994). Shifting visual attention between objects and locations: Evidence from normal and parietal lesion participants. Journal of Experimental Psychology: General, 123, $161-177$

ERIKSEN, B. A., \& ERIKSEN, C. W. (1974). Effects of noise letters upon the identification of a target letter in a nonsearch task. Perception \& Psychophysics, 16, 143-149.

ErIKSEN, C. W., \& Hoffman, J. E. (1972). Some characteristics of selective attention in visual perception determined by vocal reaction time. Perception \& Psychophysics, 11, 169-171.

Eriksen, C. W., \& Schultz, D. W. (1978). Temporal factors in visual information processing: A tutorial review. In J. Requin (Ed.), Attention and performance VII (pp. 3-23). Hillsdale, NJ: Erlbaum.

ERIKSEN, C. W., \& St. James, J. D. (1986). Visual attention within and around the field of focal attention: A zoom lens model. Perception \& Psychophysics, 40, 225-240.

Eriksen, C. W., \& YeH, Y.-Y. (1985). Allocation of attention in the visual field. Journal of Experimental Psychology: Human Perception \& Performance, 11, 583-587.

Fuentes, L. J., Humphreys, G. W., Agis, I. F., Carmona, E., \& CATENA, A. (1998). Object-based perceptual grouping affects negative priming. Journal of Experimental Psychology: Human Perception \& Performance, 24, 664-672.

HaRms, L., \& Bundesen, C. (1983). Color segregation and selective attention in a nonsearch task. Perception \& Psychophysics, 33, 11-19.

Heinze, H.-J., Luck, S. J., Münte, T. F., Gös, A., Mangun, G. R., \& HILLYARD, S. A. (1994). Attention to adjacent and separate positions in space: An electrophysiological analysis. Perception \& Psychophysics, 56, 42-52.

Kahneman, D., \& Henik, A. (1981). Perceptual organization and attention. In M. Kubovy \& J. R. Pomerantz (Eds.), Perceptual organization (pp. 181-211). Hillsdale, NJ: Erlbaum.

Kahneman, D. Treisman, A., \& Burkell, J. (1983). The cost of visual filtering. Journal of Experimental Psychology: Human Perception \& Performance, 9, 510-522

Keele, S. W., \& Neill, W. T. (1978). Mechanisms of attention. In E. C. Carterette \& P. Friedman (Eds.), Handbook of perception (Vol. 9, pp. 3-47). New York: Academic Press.

KIM, M.-S., \& CAVE, K. R. (1995). Spatial attention in visual search for features and feature conjunctions. Psychological Science, 6, 376-380.

Kramer, A. F., \& HaHN, S. (1995). Splitting the beam: Distribution of attention over noncontiguous regions of the visual field. Psychological Science, 6, 381-386.

Kramer, A. F., \& JACOBSON, A. (1991). Perceptual organization and focused attention: The role of objects and proximity in visual processing. Perception \& Psychophysics, 50, 267-284.

Kramer, A. F., Weber, T. A., \& Watson, S. E. (1997). Object-based attentional selection-Grouped arrays or spatially invariant representations? Comment on Vecera and Farah (1994). Journal of Experimental Psychology: General, 126, 3-13.

LAVIE, N., \& CoX, S. (1997). On the efficiency of visual selective attention: Efficient visual search leads to inefficient distractor rejection. Psychological Science, 8, 395-398.

Lavie, N., \& Driver, J. (1996). On the spatial extent of attention in object-based visual selection. Perception \& Psychophysics, 58, 12381251 .
Moore, C. M., Yantis, S., \& Vaughan, B. (1998). Object-based visual selection: Evidence from perceptual completion. Psychological Science, 9, 104-110.

MoRAn, J., \& Desimone, R. (1985). Selective attention gates visual processing in the extrastriate cortex. Science, 229, 782-784.

NeILL, W. T. (1977). Inhibitory and facilitatory processes in selective attention. Journal of Experimental Psychology: Human Perception \& Performance, 3, 444-450.

PAN, K., \& ERIKSEN, C. W. (1993). Attentional distribution in the visual field during same-different judgments as assessed by response competition. Perception \& Psychophysics, 53, 134-144.

POSNER, M. I. (1980). Orienting of attention. Quarterly Journal of Experimental Psychology, 32A, 3-25.

Posner, M. I., SNyder, C. R. R., \& Davidson, B. J. (1980). Attention and the detection of signals. Journal of Experimental Psychology: General, 109, 106-174.

PRINZMeTAL, W. (1981). Principles of feature integration in visual perception. Perception \& Psychophysics, 30, 330-340.

THEeUWES, J. (1991). Exogenous and endogenous control of attention: The effects of visual onsets and offsets. Perception \& Psychophysics, 49, 83-90.

TIPPER, S. P. (1985). The negative priming effect: Inhibitory priming by ignored objects. Quarterly Journal of Experimental Psychology, 37A, 557-590.

Tipper, S. P., Driver, J., \& Weaver, B. (1991). Object-centered inhibition of return of visual attention. Quarterly Journal of Experimental Psychology, 43A, 289-298.

Tipper, S. P., Weaver, B., Jerreat, L. M., \& Burak, A. L. (1994). Object-based and environment-based inhibition of return of visual attention. Joumal of Experimental Psychology: Human Perception \& Performance, 20, 478-499.

Treisman, A., Kahneman, D., \& Burkell, J. (1983). Perceptual objects and the cost of filtering. Perception \& Psychophysics, 33, 527532.

Valdes-Sosa, M., Bobes, M. A., Rodriguez, V., \& Pinilla, T. (1998). Switching attention without shifting the spotlight: Object-based attentional modulation of brain potentials. Journal of Cognitive Neuroscience, 10, 137-151.

Vecera, S. P., \& Farah, M. J. (1994). Does visual attention select objects or locations? Journal of Experimental Psychology: General, 123, 146-160.

YANTIS, S., \& Jonides, J. (1984). Abrupt visual onsets and selective attention: Evidence from visual search. Journal of Experimental $P_{s y-}$ chology: Human Perception \& Performance, 10, 601-620.

\section{NOTES}

1. The phrase nonsearch task is used here to emphasize the differences between the present paradigm and visual search. Whereas both paradigms involve the manipulation of distractor set-size, they differ in a number of important ways. In visual search, observers typically respond to the presence or absence of a target, and the target location changes randomly from trial to trial. In contrast, in the present paradigm, targets appeared on every trial, and their locations relative to the distractors remained the same in each experiment.

It is also worth noting that we typically do not take the distractor setsize effect in a standard conjunction search task as evidence for objectbased selection, even though observers' response latencies correlate positively with the number of distractors in a stimulus display. This may, in part, be due to the fact that, in a typical conjunction search paradigm, sensory interactions between the target and the distractors are usually not controlled across conditions, leaving open the question of whether the effect could be object-based, location-based, or both.

2. Color was not associated with any statistically significant results, either as a main effect or as an interaction. This is true in all the experiments reported in this paper. Accordingly, the data shown in the paper are pooled across colors.

(Manuscript received August 4, 1998; revision accepted for publication March 10, 1999,) 